\title{
Wide QRS complex tachycardia and R-R variations
}

\author{
iremar MACEDO NETO ${ }^{1}$, Abelardo Escarião ${ }^{1}$, Afonso Albuquerque ${ }^{1}$, André Rezende ${ }^{1}$, \\ Ezequiel Thé $^{1}$, and Anderson Armstrong ${ }^{2}$ \\ ${ }^{1}$ University of Pernambuco \\ ${ }^{2}$ Universidade Federal do Vale do Sao Francisco
}

July 21, 2020

\section{Case report}

A 74-year-old man presented with frequent palpitations, described as "the heart beating on the neck." He also had a history of two syncope episodes; the most recent was more than six months before his admission. By careful history taking, we found that the syncope episodes did not seem to occur as a result of vasovagal reflex. The patient's resting electrocardiogram (ECG) showed a right bundle branch block (RBBB) pattern (Figure 1 ). Holter monitoring and exercise tests revealed a bundle branch block alternating between the right and left bundles. His echocardiogram was normal with preserved ejection fraction (EF) (66\%).

After this initial evaluation, he was subjected to an electrophysiological study (EPS) and the basic intervals measured were as follows: PR, $186 \mathrm{~ms}$; QRS, $153 \mathrm{~ms}$ (RBBB); AH, $86 \mathrm{~ms}$ (basal); and HV, $60 \mathrm{~ms}$. Atrial electrical stimulation (AES) induced a wide QRS complex tachycardia (Figure 2A ), with predominantly RBBB morphology, some of the QRS having a left bundle branch block (LBBB) pattern, and some atrial beats being blocked to the ventricles below the bundle of His (Figure 2B ).

\section{What is the most likely diagnosis?}

We observed an irregular, wide QRS complex tachycardia induced by AES; some of the ventricular beats presented with RBBB morphology, while others with an LBBB pattern; and some of the atrial beats were blocked to the ventricles. The blocked atrial impulse automatically excludes ventricular tachycardia and atrioventricular reentrant tachycardia (AVRT), since the ventricles are not an essential part of the circuit. At this point, there are two possible diagnostic approaches: atrial tachycardia (AT) or atrioventricular nodal reentrant tachycardia (AVNRT).

It should be noted that this patient had a severe conduction system disease, which could be confirmed by observing the HV interval. Most of the time, the QRS has an RBBB pattern, with an HV interval of $60 \mathrm{~ms}$, but when the QRS changes to the LBBB pattern, the HV interval lengthens to 114 ms. Blocked atrial beats below the His bundle could also be seen and are responsible for the R-R interval irregularity.

Careful observation of tachycardia activation can help establish a correct diagnosis. First, the tachycardia induction repeatedly occurs with an increase in the A-H interval, suggesting AVNRT as the cause of the $\operatorname{arrhythmia}^{12}$.

Additionally, we can observe that there is some variation in the A-A interval, but it is always preceded by changes in the $\mathrm{H}-\mathrm{H}$ interval, which is not seen in ATs. Importantly, the $\mathrm{H}-\mathrm{H}$ interval variation is closely related to changes in the A-H interval, suggesting that there is more than one slow pathway capable of antegrade conduction. The H-A interval (retrograde conduction) remained unchanged during tachycardia for $75 \mathrm{~ms}$, suggesting that the antegrade conduction is the cause of the $\mathrm{H}-\mathrm{H}$ variation. This observation rules out AT and leaves us with AVNRT as the cause of this patient's arrhythmia ${ }^{12}$. 
We decided not to perform slow pathway ablation at that moment, due to the risk of a complete heart block.

The patient underwent dual chamber pacemaker implantation without complications. A few days after pacemaker implantation, the patient was recruited in a new EPS with slow pathway ablation without complications.

An intriguing finding in this case is that the patient had persistent palpitations after pacemaker implantation and before the slow pathway ablation, proving that his symptoms were related to AVNRT. More than one year after the ablation procedure, the patient remains asymptomatic and free of antiarrhythmic drugs.

This was an atypical presentation of a typical AVNRT. The electrogram tracings showed the exact mechanism of the arrhythmia, thereby immediately ruling out AVRT and AT, which is the most important differential diagnosis. We also demonstrated the mechanism by which there is variation in the cycle length, showing that it depends on the antegrade conduction over more than one slow pathway, as proven by the exact lengthening of the A-H interval determining the same amount of lengthening in the $\mathrm{A}-\mathrm{A}$ and $\mathrm{H}-\mathrm{H}$ intervals.

Such a unique presentation of AVNRT in the presence of significant conduction disorders results in a challenging ECG tracing, as it would be impossible to establish a precise diagnosis without performing an EPS. To the best of our knowledge, this is the first report showing the association of many electrophysiological phenomena during AVNRT, making diagnosis by ECG difficult. The only way to determine the origin of all ECG findings is by careful analysis of the intracavitary signals.

\section{Acknowledgement}

Special thanks to André A.L. Carmo, for help in writing this article. We would also like to thank Editage (www.editage.com) for English language editing.

\section{Funding}

This research did not receive any specific grant from funding agencies in the public, commercial, or not-forprofit sectors.

\section{References}

1. Josephson ME. Clinical Cardiac Electrophysiology. 4th ed. Philadelphia: Lippincott Williams \& Wilkins, 2008: $175-226$.

2. Issa ZF, Miller JM, Zipes DP. Clinical Arrhythmology and Electrophysiology. Philadelphia: Saunders Elsevier, 2009: $293-311$.

\section{Figure legend}

Figure 1. Wide QRS complex tachycardia with predominantly right bundle branch block (RBBB) morphology, but with some beats with left bundle branch block (LBBB) pattern, and some being blocked to the ventricles.

Figure 2. Last atrial paced beat inducing tachycardia (A). Wide complex tachycardia (B).

Figure 3. Atrioventricular nodal reentrant tachycardia (AVNRT) with cycle length variation based on $\mathrm{H}-\mathrm{H}$ interval change. The $\mathrm{H}-\mathrm{A}$ interval is fixed (linking $\mathrm{H}-\mathrm{A}$ ), but $\mathrm{A}-\mathrm{H}$ interval varies because antegrade conduction is moving between more than one slow pathway and this determines the A-A interval variation.

\section{Hosted file}

Figure 1 word.docx available at https://authorea.com/users/344583/articles/471062-wide-qrscomplex-tachycardia-and-r-r-variations

\section{Hosted file}

Figure 2.docx available at https://authorea.com/users/344583/articles/471062-wide-qrscomplex-tachycardia-and-r-r-variations 


\section{Hosted file}

Figure 3 .docx available at https://authorea.com/users/344583/articles/471062-wide-qrscomplex-tachycardia-and-r-r-variations 